\title{
Population dynamic of green tiger prawn, Penaeus semisulcatus (De Haan) in Bushehr coastal waters, Persian Gulf
}

\begin{abstract}
Monthly carapace length frequency data of green tiger prawn, Penaeus semisulcatus were collected from the coastal waters of Bushehr, Persian Gulf, from January 2002 to March 2003. ELEFAN in the software package FiSAT was used to analyse of their length frequency data. The $\mathrm{L} \infty$ and $\mathrm{K}$ for males were estimated at $38 \mathrm{~mm} \mathrm{CL}$ and 1.6 year-1, respectively and for the females $50.40 \mathrm{~mm} \mathrm{CL}$ and 2.20 year-1. Using the $\mathrm{L} \infty$ and $\mathrm{K}$ estimates for both sexes and average water temperature of $24.1{ }^{\circ} \mathrm{C}$ the instantaneous rate of natural mortality (M) for males and females were calculated as 2.11 and 2.41 year-1, respectively. The instantaneous rates of total mortalities $(Z)$ were estimated from length-converted catch curves and the values at 6.4 year -1 for males and 8.2 year-1 for females, and the instantaneous rates of fishing mortalities $(\mathrm{F})$ for males were 4.3 year -1 and for females 5.8 year -1 . Thus, the exploitation rates (E) were 0.67 year-1 and 0.7 year-1 for males and females, respectively. Maximum age (Tmax) was 20 months for the males and 15 months for the females. Based on the results of the present study, P. semisulcatus growth is rapid during summer and autumn and negligible during winter and spring. Natural mortality rates were not grossly different for both sexes, although the males were more vulnerable to fishing than the females. Also the results showed that P. semisulcatus was overexploited in the study area. The exploitation of P. semisulcatus in Bushehr waters is intended to protect the spawners and juveniles stock for renewal.
\end{abstract}

Keyword: Population dynamics, P. semisulcatus, Persian Gulf, Iranian waters 